\title{
A produção científica brasileira sobre gestão de riscos no setor público: uma análise bibliométrica
}

\author{
Naiara Taise Sousa Nunes \\ Samuel Cavalcante Mota \\ Augusto Cézar de Aquino Cabral \\ Sandra Maria dos Santos \\ Universidade Federal do Ceará, Fortaleza, CE - Brasil
}

O gerenciamento de riscos tem se mostrado como ferramenta essencial para o alcance dos objetivos das instituições. No setor público, ela pode auxiliar na gestão mais eficiente dos recursos, que reflete na melhoria da prestação de serviços ao cidadão. Este estudo teve como objetivo investigar a produção científica de artigos sobre gestão de riscos com enfoque no setor público, publicada em periódicos nacionais. O estudo é caracterizado como uma pesquisa bibliométrica, exploratória-descritiva, documental, com abordagem quantitativa. Foram utilizados os bancos de dados SPELL (Scientific Periodicals Eletronic Library) e Plataforma Capes no período de 2008 a 2018. Observou-se um aumento na produção científica sobre a temática no período compreendido entre 2008 e 2016, a partir de quando se observa um declínio. O perfil de autoria predominante foi de dois autores, doutores e vinculados a instituições da Região Sudeste, em especial São Paulo. Foram encontradas publicações em um grande número de periódicos com predominância de classificação Qualis B2. Prevalecem pesquisas qualitativas do tipo exploratória com a utilização do estudo de caso. A maior parcela dos estudos realizou-se em entes públicos da esfera estadual e municipal. Identificou-se, também, que uma parcela significativa dos estudos se baseia no modelo coso.

Palavras-chaves: gestão de riscos, setor público, estudo bibliométrico 


\section{La producción científica brasileña sobre gestión de riesgos en el sector público: un análisis bibliométrico}

La gestión de riesgos ha demostrado ser una herramienta esencial para el logro de los objetivos de las instituciones. En el sector público, puede ayudar a una gestión de recursos más eficiente, lo que se refleja en una mejor prestación de servicios al ciudadano. Este estudio tuvo por objetivo investigar la producción científica de artículos de gestión de riesgos centrados en el sector público, publicados en revistas nacionales. El estudio se caracteriza por ser una investigación documental bibliométrica, exploratória descriptiva con un enfoque cuantitativo. Las bases de datos SPELL (Scientific Periodicals Electronic Library) y Platforma Capes se utilizaron de 2008 a 2018. Hubo un aumento en la producción científica sobre el tema entre 2008 y 2016, desde el momento en que se observa una disminución. El perfil de autor predominante fue de dos autores, doctores y vinculados a instituciones de la Región Sudeste, especialmente São Paulo. Se encontraron publicaciones en un gran número de revistas con predominio de la clasificación Qualis B2. La investigación exploratoria cualitativa prevalece con el uso de casos de estudio. La mayoría de los estudios se realizaron en entidades públicas estatales y municipales. Se encontró también que una parte importante de los estudios se basa en el modelo coso.

Palabras clave: gestión de riesgos, sector público, estudio bibliométrico

\section{The Brazilian scientific production on risk management in the public sector: a bibliometric analysis}

Risk management is presented as an essential tool for achieving the objectives of institutions. In the public sector, it can assist in the management of resources, which improve the execution of services to the citizen. This study aimed to investigate the scientific production of risk management articles with a focus on the public, published in national journals. The study is characterized as a bibliometric research, exploratory-descriptive, documentary, with quantitative. SPELL (Scientific Periodicals Electronic Library) and Capes Platform databases were used from 2008 to 2018. There was an increase in scientific production on the subject in the period from 2008 to 2016 . The predominant authorship profile was two authors, doctors and linked to institutions in the Southeast Region, especially São Paulo. What is a large number of journals with predominance of Qualis B2 classification. Qualitative research of the exploratory type prevails with the use of the case study. Most of the studies carried out are at the federal and municipal levels. It was also identified that a large part of the studies is based on the COSO model.

Keywords: risk management, public sector, bibliometric study 


\section{Introdução}

Ao longo dos anos, a gestão dos serviços públicos tem enfrentado diversas mudanças e reformas, aproximando-se cada vez mais das entidades privadas. E, com isso, surge a necessidade de uma aplicação de recursos mais eficiente e transparente. Essas mudanças refletem a necessidade que as instituições públicas têm de adequar-se a um mundo onde o desenvolvimento econômico tem acelerado substancialmente e a tecnologia muda constantemente, tornando as relações econômicas e sociais cada vez mais complexas.

Nesse contexto, a gestão de riscos atua como ferramenta importante para auxiliar os gestores na identificação de eventos ou situações capazes de fornecer razoável certeza quanto ao alcance dos objetivos definidos pelas instituições.

A premissa inerente ao gerenciamento de riscos corporativos é que toda organização existe para gerar valor às partes interessadas. Todas as organizações enfrentam incertezas, e o desafio de seus administradores é determinar até que ponto aceitar essa incerteza, assim como definir como essa incerteza pode interferir no esforço para gerar valor às partes interessadas (COMMITTEE OF SPONSORING ORGANIZATIONS OF THE TREADWAY COMISSION - COSO, 2007).

Segundo Ávila (2014), o sucesso na implementação do gerenciamento de risco deverá resultar em melhorias na qualidade dos serviços públicos e na eficácia das políticas públicas. Deverá igualmente apoiar um diálogo entre cidadãos e o serviço público sobre a natureza do risco e como se pode melhor operar em um ambiente de incerteza e de recursos limitados.

Diante do exposto, pretende-se responder a seguinte questão: como se caracteriza a produção científica brasileira sobre gestão de riscos no setor público? Sob esse prisma, a pesquisa tem como objetivo geral investigar a produção científica de artigos sobre gestão de riscos com enfoque para o setor público.

Para alcançar o objetivo geral, foram traçados os seguintes objetivos específicos: i) analisar o perfil de autoria que mais se destacou na produção acadêmica acerca da temática; ii) examinar o perfil dos periódicos com publicações sobre gestão de riscos no 
setor público; iii) identificar os aspectos metodológicos; iv) conhecer o tipo de organização ou setor mais estudado quanto ao aspecto gestão de riscos no setor público; v) examinar os principais eixos temáticos correlatos à abordagem sobre gestão de riscos no setor público; vi) conhecer os modelos teóricos predominantes nos estudos; e vii) verificar a dinâmica da produção científica relacionada ao tema.

Espera-se que os resultados desta investigação proporcionem novas percepções sobre a referida temática, buscando identificar as principais tendências da área, os temas mais abordados, a quantidade e heterogeneidade de temáticas relacionadas, permitindo, assim, identificar os pontos que precisam ser mais bem estudados. Dessa forma, é possível identificar oportunidades para realização de novas pesquisas, o que representa um avanço para o tema gestão de riscos.

Para consecução do objetivo desta pesquisa, foi realizado um estudo exploratóriodescritivo que adotou uma abordagem quantitativa utilizando-se o método bibliométrico. O procedimento técnico adotado foi uma pesquisa documental nos periódicos publicados no período de 2008 a 2018 cadastrados no banco de dados SPELL e na Plataforma Capes.

Além desta introdução, o artigo está estruturado em seis seções, incluindo a conclusão e as referências utilizadas. A segunda seção trata sobre os principais conceitos sobre gestão de risco e a legislação aplicável ao setor público, os modelos mais utilizados e estudos anteriores relacionados à temática.

A terceira seção dedica-se aos aspectos metodológicos da pesquisa, sua tipologia, população, amostra e o detalhamento dos procedimentos e métodos utilizados.

A quarta seção refere-se à apresentação e interpretação dos resultados da pesquisa, que abrangem: quantidade de autores por artigo, os pesquisadores mais produtivos, nível de formação, instituição vinculada, estado e Região dos autores; o perfil dos periódicos com mais publicações sobre a temática, o ano de publicação, a classificação metodológica em relação à abordagem, procedimentos, objetivos e coleta de dados, os tipos de organizações estudadas, os eixos temáticos e os modelos teóricos mais adotados. 


\section{Referencial teórico}

Para realizar o exame da produção científica relativa à gestão de riscos no setor público, esta seção de referencial teórico contempla os seguintes pontos: gestão de riscos, gestão de riscos no setor público, modelos de gestão de riscos e estudos bibliométricos anteriores sobre o tema gestão de riscos.

\subsection{Gestão de riscos}

Segundo o COSO (2007), toda organização está exposta a incertezas que podem afetar o objetivo para o qual esta foi criada. 0 desafio é estabelecer o nível de incerteza que se está disposto a aceitar. Essas incertezas ou eventos são conceituados de diferentes formas.

Risco, na visão de Damodaran (2009), é a possibilidade de que os resultados sejam diferentes dos esperados, podendo envolver graves perdas ou novas oportunidades. Segundo o autor, o estudo do risco é fascinante porque, além das situações de riscos involuntárias, há as criadas pelo livre-arbítrio do ser humano.

Segundo Carvalho Neto e Silva (2009), o gerenciamento de risco é um processo necessário, lógico e sistemático para organizações identificarem e avaliarem riscos e oportunidades, visando melhorar a tomada de decisões e a avaliação de desempenhos.

É de fundamental importância para a implantação de uma gestão de riscos eficaz a definição de conceitos, critérios e objetivos claros. No âmbito das organizações do setor público, essa definição precisa estar ainda mais clara frente à necessidade de adequação aos princípios a que estão obrigadas, especialmente o da legalidade.

Organizações de todos os tipos e tamanhos enfrentam influências e fatores internos e externos que tornam incertos se e quando atingirão seus objetivos. $O$ efeito que esta incerteza tem sobre os objetivos da organização é chamado de risco (AssociAçÃo BRASILEIRA DE NORMAS TÉCNICAS - ABNT, 2009).

A gestão de riscos refere-se ao processo de aplicação sistemática de políticas, procedimentos e práticas de gestão para as atividades de comunicação, consulta, 
estabelecimento do contexto, e na identificação, avaliação, tratamento, monitoramento e análise crítica dos riscos (ASSOCIAÇÃo BRASILEIRA DE NORMAS TÉCNICAS, 2009). Além da identificação e decisão quanto ao tratamento dos riscos, a gestão de riscos envolve também a contínua avaliação da eficácia dos controles internos implantados na organização para mitigar os riscos relevantes.

Algumas normas sobre gestão de riscos são reconhecidas mundialmente, como é o caso do Enterprise Risk Management (ERM), Management of Risk - Principles and Concepts (Orange Book) e Gestão de Riscos - Princípios e Diretrizes (ISO 31000), editadas pelo COSO, pelo Tesouro Britânico (HM Treasury) e pela ABNT, respectivamente. As mesmas foram elaboradas com o objetivo de oferecer uma metodologia ou sistemática adequada para a implantação e aprimoramento da gestão de riscos (COMMITTEE OF SPONSORING ORganizATIONS OF THE TREADWAY COMISSION, 2007).

\subsection{Gestão de riscos no setor público}

Nas organizações públicas os riscos também estão presentes e, se não forem devidamente gerenciados, acarretam consequências que refletem em toda a sociedade. Tanto cidadãos quanto a sociedade perdem tempo e dinheiro, se programas do governo e serviços públicos associados não são entregues de forma adequada e em tempo hábil (GESPÚBLICA, 2013). Essa ingerência impacta diretamente o alcance dos objetivos, influenciando, entre outros aspectos, no cumprimento dos prazos, no controle dos custos e na qualidade dos serviços prestados.

O gerenciamento de riscos pode ajudar as organizações públicas a melhorar a eficiência, a eficácia e efetividade de diversas formas, como: melhoria na entrega de serviços ao cidadão, melhor utilização de recursos, melhor planejamento e melhor gerenciamento de programas e projetos, além disso, aumenta a confiança do cidadão na capacidade do governo de entregar os serviços prometidos, no sistema de governança e na utilização adequada dos recursos públicos (GESPúBLICA, 2013).

Em alguns países a gestão de riscos já é prática consolidada no setor público, como é o caso do Canadá, que adotou oficialmente modelo de gestão de riscos em 2001 (Integrated Risk Management Framework, abril de 2001), promovendo, ainda, uma 
revisão ampla do tema em 2010 editando novos documentos de referência (Framework for the Management of Risk); e do Reino Unido, que também tem adotado gestão de riscos no seu setor público há alguns anos. Em 2009, o tesouro britânico publicou ferramenta voltada para a avaliação da gestão de risco nos diversos setores do governo (Risk Management assessment framework: a tool for departments), consolidando, assim, o uso dessa abordagem na sua administração pública.

No Brasil, percebe-se o esforço do legislador federal em emitir normas para definição e exigência de critérios de governança e gestão de riscos, entre elas: a Instrução Normativa no 01, publicada em 11 de maio de 2016, que dispõe sobre controles internos, gestão de riscos e governança; e o Decreto no 9.203, de 22 de novembro de 2017, que dispõe sobre a política de governança da administração pública, ambos citados no trabalho de Martins et al. (2018). A Instrução Normativa no 05, de 26 de maio de 2017, que dispõe sobre as regras e diretrizes do procedimento de contratação de serviços sob o regime de execução indireta, também trata sobre o tema.

De acordo com os estudos de Silva, Abreu e Couto (2017), a emissão de novos normativos nos anos seguintes ao anúncio da Operação Lava Jato foi superior ao número de normas emitidas nos dois anos anteriores ao anúncio, demonstrando que o aprimoramento do controle interno no setor público, mediante a emissão de novas leis, decretos e outros normativos, pode estar relacionado, como esperado pelo senso comum, com a maior apuração e divulgação de casos de corrupção após os primeiros resultados da Operação Lava Jato.

\subsection{Modelos de gestão de riscos}

Destacam-se como principais fontes utilizadas sobre gestão de riscos: a ABNT ISO 31000, que passou por uma atualização em 2018; o COSO ERM; e o Orange Book, já que representam os modelos de gestão de riscos predominantes no cenário corporativo internacional atualmente.

O Quadro 1 apresenta os principais pontos fortes e fracos atribuídos a cada modelo, de acordo com o estudo de Silva (2015). É importante que sejam analisados os aspectos da estrutura de gestão de riscos antes da escolha do modelo a ser seguido, 
aspectos estes que abrangem: ambiente interno, arcabouço para definição dos objetivos passíveis de gerenciamento, política de gestão de riscos, comitê de gestão de riscos e sistema de informação.

Quadro 1 | Pontos fortes e fracos de cada modelo

\begin{tabular}{|l|l|l|}
\hline Modelo & Pontos fortes & Pontos fracos \\
\hline $\begin{array}{l}\text { ERM } \\
\text { (COSO) }\end{array}$ & $\begin{array}{l}\text { Ambiente interno; } \\
\text { fixação de objetivos; } \\
\text { técnicas de identificação de } \\
\text { riscos; respostas ao risco; } \\
\text { monitoramento do risco. }\end{array}$ & $\begin{array}{l}\text { Não faz distinção entre a } \\
\text { estrutura e o processo de } \\
\text { gestão de riscos. }\end{array}$ \\
\hline $\begin{array}{l}\text { ISO 31000 } \\
\text { (ABNT) }\end{array}$ & $\begin{array}{l}\text { Princípios; } \\
\text { política de gestão de riscos. }\end{array}$ & $\begin{array}{l}\text { Não detalha as respostas ao } \\
\text { risco. }\end{array}$ \\
\hline $\begin{array}{l}\text { Orange Book } \\
\text { (Tesouro Britânico) }\end{array}$ & $\begin{array}{l}\text { Conceito de proprietário do } \\
\text { risco; resposta ao risco; } \\
\text { metodologia para classificação do risco; } \\
\text { comitê de gestão de riscos. }\end{array}$ & Foco governamental. \\
\hline
\end{tabular}

Fonte: Silva (2015, p.80).

Segundo Silva (2015), enquanto o gerenciamento de riscos corporativos amplia o alcance dos controles internos de uma organização, de modo a adotar um processo completo de gerenciamento de riscos, a ISO 31000 estabelece um número de princípios que precisam ser atendidos para tornar a gestão de riscos mais eficaz. Já o Orange Book é um modelo de gerenciamento de riscos com viés governamental e apresenta metodologia específica para a classificação dos riscos.

De acordo com a ISO 31000 (2009), a gestão de riscos compreende atividades coordenadas para dirigir e controlar uma organização no que se refere a riscos. Já o COSO (2007) conceitua como sendo um processo conduzido em uma organização pelo conselho de administração, diretoria e demais empregados, aplicado no estabelecimento de estratégias formuladas para identificar em toda a organização eventos em potencial capazes de afetá-la e para administrar os riscos de modo a mantê-los compatíveis com o apetite a risco da organização, possibilitando garantia razoável do cumprimento dos seus objetivos. 


\subsection{Estudos bibliométricos anteriores sobre gestão de riscos}

Conscientes da importância da gestão de riscos no contexto das organizações, vários autores já se debruçaram no sentido de entender a produção científica fundamentada nesse tema. O Quadro 2 apresenta uma síntese de alguns desses estudos, que foram encontrados em consulta na base SPELL e na base Capes.

\section{Quadro 2 | Estudos anteriores}

\begin{tabular}{|c|c|c|c|}
\hline Autores (ano) & Objetivo geral & Metodologia & Resultados \\
\hline Ribeiro (2017) & $\begin{array}{l}\text { Investigar o perfil e as } \\
\text { particularidades da } \\
\text { produção acadêmica } \\
\text { sobre o tema gestão } \\
\text { de riscos, divulgada } \\
\text { nas revistas científicas } \\
\text { disponibilizadas na Base } \\
\text { Atena de } 2000 \text { a } 2015\end{array}$ & $\begin{array}{l}\text { Técnicas de mensuração } \\
\text { e análise bibliométrica } \\
\text { e sociométrica em } 52 \\
\text { artigos identificados no } \\
\text { estudo. }\end{array}$ & $\begin{array}{l}\text { Tanto a rede de coautoria } \\
\text { como a rede das IESs } \\
\text { têm baixa densidade, } \\
\text { influenciando em suas } \\
\text { respectivas dispersões. } \\
\text { Foram identificados } 29 \\
\text { temas que se vinculam } \\
\text { ao assunto. }\end{array}$ \\
\hline $\begin{array}{l}\text { Valentim, Silva e } \\
\text { Passos (2016) }\end{array}$ & $\begin{array}{l}\text { Identificar e analisar } \\
\text { as características das } \\
\text { pesquisas sobre controle } \\
\text { interno e gestão de } \\
\text { risco, nas principais } \\
\text { revistas brasileiras de } \\
\text { contabilidade entre os } \\
\text { anos } 2002 \text { e } 2015 \text {. }\end{array}$ & $\begin{array}{l}\text { O processo metodológico } \\
\text { foi estruturado em } \\
\text { três fases: a) escolha } \\
\text { dos dez principais } \\
\text { periódicos brasileiros } \\
\text { em contabilidade; b) } \\
\text { estruturação de um } \\
\text { portfólio de artigos a } \\
\text { partir dos parâmetros } \\
\text { definidos; e c) } \\
\text { revisão dos estudos } \\
\text { antecedentes sobre } \\
\text { controle interno e gestão } \\
\text { de riscos. }\end{array}$ & $\begin{array}{l}\text { o coso foi intitulado } \\
\text { como instrumento de } \\
\text { controle e gestão em } \\
\text { diversos trabalhos. } \\
\text { Contudo, os resultados } \\
\text { mostraram que diversos } \\
\text { fatores devem ser } \\
\text { considerados para } \\
\text { implementar, ou } \\
\text { fortalecer, o processo } \\
\text { de gerenciamento de } \\
\text { risco nas organizações } \\
\text { efetivamente. }\end{array}$ \\
\hline $\begin{array}{l}\text { Peleias et al. } \\
(2013)\end{array}$ & $\begin{array}{l}\text { Identificar e analisar } \\
\text { as características } \\
\text { bibliométricas de } \\
\text { artigos sobre controle } \\
\text { interno e gestão de } \\
\text { riscos apresentados } \\
\text { no Congresso USP } \\
\text { (de Controladoria e } \\
\text { Contabilidade e de } \\
\text { Iniciação Científica) e no } \\
\text { EnANPAD, entre } 2001 \text { e } \\
2011 .\end{array}$ & $\begin{array}{l}\text { De } 9.894 \text { artigos } \\
\text { apresentados nos } \\
\text { eventos durante o } \\
\text { período especificado, } \\
\text { foram selecionados 165, } \\
\text { por meio de palavras- } \\
\text { chave previamente } \\
\text { especificadas. }\end{array}$ & $\begin{array}{l}\text { Constatou-se, por meio } \\
\text { da Lei de Lotka, que } \\
\text { ainda não há, nos dois } \\
\text { eventos, uma elite de } \\
\text { pesquisadores contábeis } \\
\text { estudando e publicando } \\
\text { sobre controle interno } \\
\text { e gestão de riscos, fato } \\
\text { constatado em outros } \\
\text { temas contábeis. }\end{array}$ \\
\hline
\end{tabular}

Fonte: elaboração própria. 
Conforme observa-se no Quadro 2, Ribeiro (2017) dedicou-se a pesquisar a produção acadêmica sobre gestão de riscos de forma ampla, sem associação a nenhum outro tema e utilizou como fonte as revistas científicas disponibilizadas na Base Atena, no perídio de 2000 a 2015. Já os estudos de Valentim, Silva e Passos (2016) e Peleias et al (2013) dedicaram-se à análise da gestão de riscos associada ao tema controles internos. No entanto, utilizaram bases e períodos distintos. Os primeiros analisaram revistas brasileiras de contabilidade entre os anos 2002 e 2015. E os segundos estudaram os artigos apresentados no Congresso USP (de Controladoria e Contabilidade e de Iniciação Científica) e no EnANPAD, entre 2001 e 2011.

Essas pesquisas servem para fomentar a discussão, o aperfeiçoamento e a difusão do conhecimento científico sobre o tema. No entanto, seja por estarem relacionadas a outras temáticas ou ainda por se basearem em uma fonte de dados específica de uma área de conhecimento, as pesquisas anteriores não contemplam o objetivo desta pesquisa.

A pesquisa realizada proporciona novas percepções sobre a referida temática, buscando identificar as principais tendências da área, os temas mais abordados, a quantidade e heterogeneidade de temáticas relacionadas, permitindo, assim, identificar os pontos que precisam ser mais bem estudados. Dessa forma, é possível identificar oportunidades para realização de novas pesquisas, o que representa um avanço para o tema gestão de riscos.

Ademais, considerando que não foram encontrados trabalhos voltados à gestão de riscos sob a perspectiva de aplicabilidade ao setor público, a pesquisa revela-se como relevante tendo em vista seu ineditismo.

\section{Metodologia}

A pesquisa foi conduzida pelo método de pesquisa bibliométrico, que, segundo Araújo (2006), mede índices de produção e disseminação do conhecimento, de modo a quantificar os processos de comunicação escrita e identificar as suas características. 
Quanto ao objetivo desta investigação, a pesquisa classifica-se como exploratóriadescritiva. Acevedo e Nohara (2006, p. 46) retratam que o principal objetivo da pesquisa exploratória "é proporcionar maior compreensão do fenômeno que está sendo investigado, permitindo, assim, que o pesquisador delineie de forma mais precisa o problema". As pesquisas descritivas, segundo Gil (1987, p. 45), "têm como objetivo primordial a descrição das características de determinada população ou fenômeno ou o estabelecimento de relações entre variáveis".

No que se refere à abordagem, esta pesquisa enquadra-se como quantitativa, tendo em vista o emprego da quantificação tanto nas modalidades de coleta de informações, quanto no tratamento dessas por meio de técnicas estatísticas (RICHARDSON, 1989).

Em relação aos procedimentos, foi utilizada pesquisa documental nos periódicos publicados no período de 2008 a 2018 cadastrados no banco de dados SPELL (Scientific Periodicals Eletronic Library) e na Plataforma Capes. A pesquisa foi realizada por meio de consulta avançada utilizando-se os termos "gestão de riscos", "gestão de risco", "gerenciamento de riscos" e "gerenciamento de risco" nos campos "título do documento" e "palavra-chave", na base SPELL; e nos campos "título do documento" e "assunto", na base Capes, ambas na categoria "artigos".

A busca retornou um total de 52 artigos na base SPELL e 199 na base Capes. Estes foram analisados quanto ao campo de estudo, sendo selecionados para compor a amostra apenas aqueles com aplicabilidade ao setor público. A análise dos dados foi realizada por meio da tabulação dos artigos em uma planilha eletrônica elaborada no programa Microsoft Excel versão 16.0, com roteiro estruturado, conforme demonstrado no Quadro 


\section{Quadro 3 | Relação dos objetivos com as categorias de análise}

\begin{tabular}{|c|c|}
\hline Objetivos & Categorias \\
\hline $\begin{array}{l}\text { Objetivo 1: analisar o perfil de autoria que mais } \\
\text { se destacou na produção acadêmica acerca da } \\
\text { temática. }\end{array}$ & $\begin{array}{l}\text { - } \quad \text { Quantidade de autores; } \\
\text { - } \quad \text { nível de formação dos autores; } \\
\text { - } \quad \text { instituição dos autores; } \\
\text { - } \quad \text { estado e Região dos autores. }\end{array}$ \\
\hline $\begin{array}{l}\text { Objetivo 2: examinar o perfil dos periódicos } \\
\text { com publicações sobre gestão de riscos no setor } \\
\text { público. }\end{array}$ & $\begin{array}{l}\text { - } \quad \text { Artigos por periódico; } \\
\text { - } \quad \text { periódicos com mais publicações; } \\
\text { - } \quad \text { perfil dos periódicos. }\end{array}$ \\
\hline $\begin{array}{l}\text { Objetivo 3: identificar os aspectos metodológicos } \\
\text { utilizados. }\end{array}$ & $\begin{array}{l}\text { - } \quad \text { Abordagem; } \\
\text { - } \quad \text { objecedimentos; } \\
\text { - } \quad \text { coleta de dados. }\end{array}$ \\
\hline $\begin{array}{l}\text { Objetivo 4: conhecer o tipo de organização ou } \\
\text { setor mais estudado quanto ao aspecto gestão } \\
\text { de riscos. }\end{array}$ & - $\quad$ Tipo de organização estudada. \\
\hline $\begin{array}{l}\text { Objetivo 5: examinar os principais eixos } \\
\text { temáticos correlatos à abordagem sobre gestão } \\
\text { de riscos. }\end{array}$ & - $\quad$ Eixo temático. \\
\hline $\begin{array}{l}\text { Objetivo 6: conhecer os modelos teóricos } \\
\text { predominantes nos estudos. }\end{array}$ & - Modelos teóricos. \\
\hline $\begin{array}{l}\text { Objetivo 7: verificar a dinâmica da produção } \\
\text { científica relacionada ao tema }\end{array}$ & - $\quad$ Ano de publicação. \\
\hline
\end{tabular}

Cabe ressaltar que foi verificada certa correlação entre as bases, estando o mesmo artigo publicado em ambas. Nesses casos, o artigo foi considerado para análise apenas uma vez. Desta forma, restou, ao final, uma amostra de 43 artigos.

\section{Análise dos resultados}

Os resultados do presente trabalho foram apresentados a seguir, de acordo com os objetivos especificados para análise: : i) analisar o perfil de autoria que mais se 
destacou na produção acadêmica acerca da temática; ii) examinar o perfil dos periódicos com publicações sobre gestão de riscos no setor público; iii) identificar os aspectos metodológicos; iv) conhecer o tipo de organização ou setor mais estudado quanto ao aspecto gestão de riscos no setor público; v) examinar os principais eixos temáticos correlatos à abordagem sobre gestão de riscos no setor público; vi) conhecer os modelos teóricos predominantes nos estudos; e vii) verificar a dinâmica da produção científica relacionada ao tema.

\subsection{Perfil de autoria}

Observa-se que os estudos foram realizados por até sete pesquisadores, representando um caso atípico e inexpressivo (2,3\%), prevalecendo a produção com dois autores por artigo, que equivale a $37,2 \%$, seguida pela quantidade de três autores, com $27,9 \%$ dos trabalhos. A porcentagem de trabalhos elaborados por quatro e cinco autores é de $11,6 \%$ cada e de um autor é de 9,3\%, conforme Tabela 1.

Tabela 1 | Quantidade de autores por artigo

\begin{tabular}{ccc} 
Quantidade de autores & Quantidade de artigos & $\%$ \\
\hline 1 & 4 & 9,3 \\
\hline 2 & 16 & 37,2 \\
\hline 3 & 12 & 27,9 \\
\hline 4 & 5 & 11,6 \\
\hline 5 & 5 & 11,6 \\
\hline 7 & 1 & 2,3 \\
\hline
\end{tabular}

Fonte: elaboração própria.

Com relação à produtividade dos autores, observou-se a não continuidade de publicações sobre a temática quando considerado o mesmo pesquisador. Na amostra pesquisada, apenas o pesquisador João Souza Neto apareceu com mais de uma publicação, conforme demonstrado no Quadro 4. Os resultados corroboram o estudo de Peleias et al. (2013) que constataram que ainda não há uma elite de pesquisadores contábeis estudando e publicando sobre controle interno e gestão de riscos, fato também constatado em outros temas contábeis. 


\section{Quadro 4 | Autores mais produtivos}

\begin{tabular}{|c|c|c|c|c|}
\hline Autor & Título & Ano & Periódico & Qualis \\
\hline \multirow{2}{*}{ João Souza Neto } & $\begin{array}{l}\text { Contratação do desenvolvimento } \\
\text { ágil de software na administração } \\
\text { pública federal: riscos e ações } \\
\text { mitigadoras. }\end{array}$ & 2015 & $\begin{array}{l}\text { Revista do } \\
\text { Serviço } \\
\text { Público }\end{array}$ & B2 \\
\hline & $\begin{array}{l}\text { Modelo de governança de } \\
\text { segurança da informação para a } \\
\text { administração pública federal }\end{array}$ & 2018 & $\begin{array}{l}\text { Perspectiva } \\
\text { em Gestão } \\
\& \text { Conheci- } \\
\text { mento }\end{array}$ & B3 \\
\hline
\end{tabular}

Fonte: elaboração própria.

Em relação à formação dos autores, constata-se a predominância de pesquisadores com o grau de doutor (48,39\%), seguido por mestres $(16,13 \%)$ e doutorandos $(8,06 \%)$, conforme demonstrado na Tabela 2. O grande percentual de trabalhos elaborados por pesquisadores com grau de doutor pode estar associado à complexidade do tema, que exige um maior aprofundamento teórico.

Tabela 2 | Formação dos autores

\begin{tabular}{|cccc|}
\hline Ordem & Formação & $\begin{array}{c}\text { Quantidade de } \\
\text { autores }\end{array}$ & $\%$ \\
\hline 1 & Doutorado & 60 & 48,4 \\
\hline 2 & Mestrado & 20 & 16,1 \\
\hline 3 & Doutorando & 10 & 8,1 \\
\hline 4 & Pós-Doutorado & 9 & 7,3 \\
\hline 5 & Graduação & 8 & 6,5 \\
\hline 6 & Mestrando & 7 & 5,6 \\
\hline 7 & Não especificado & 6 & 4,8 \\
\hline 8 & Especialização & 4 & 3,2 \\
\hline
\end{tabular}

Fonte: elaboração própria. 
Na Tabela 3, foram relacionadas as instituições às quais os autores estão vinculados. As cinco instituições que mais publicaram foram o Centro Nacional de Monitoramento e Alertas de Desastres Naturais, a Universidade de Brasília, o Centro Federal de Educação Tecnológica Celso Suckow da Fonseca, a Pontifícia Universidade Católica do Rio de Janeiro e o Instituto Tecnológico de Aeronáutica (ITA). Com exceção da Universidade de Brasília, todas as outras instituições são da Região Sudeste. Os resultados confirmam o estudo de Ribeiro (2017), que constatou que tanto a rede de coautoria como a rede de instituições vinculadas têm baixa densidade, influenciando em suas respectivas dispersões.

Tabela 3 | Instituições dos autores

\begin{tabular}{|c|c|c|}
\hline Ordem & Instituição & $\begin{array}{c}\text { Quantidade de } \\
\text { autores }\end{array}$ \\
\hline 1 & Centro Nacional de Monitoramento e Alertas de Desastres Naturais & 7 \\
\hline 2 & Universidade de Brasília & 7 \\
\hline 3 & Centro Federal de Educação Tecnológica Celso Suckow da Fonseca & 6 \\
\hline 4 & Pontifícia Universidade Católica do Rio de Janeiro & 5 \\
\hline 5 & Instituto Tecnológico de Aeronáutica (ITA) & 4 \\
\hline 6 & Pontifícia Universidade Católica do Paraná & 4 \\
\hline 7 & Universidade Católica de Brasília & 4 \\
\hline 8 & Agência Nacional de Vigilância Sanitária & 3 \\
\hline 9 & Fundação Universidade Regional de Blumenau & 3 \\
\hline 10 & Instituto Politécnico de Setúbal & 3 \\
\hline 11 & Pontifícia Universidade Católica de São Paulo & 3 \\
\hline 12 & Universidade Federal do $A B C$ (UFABC) & 3 \\
\hline 13 & Centro Universitário Católica de Santa Catarina & 2 \\
\hline 14 & Faculdade Pedro Leopoldo & 2 \\
\hline 15 & Fundação Oswaldo Cruz & 2 \\
\hline 16 & Fundação Pedro Leopoldo & 2 \\
\hline 17 & Tribunal de Contas do Estado do Ceará (TCE) & 2 \\
\hline 18 & Universidade Nove de Julho & 2 \\
\hline
\end{tabular}




\begin{tabular}{|c|l|c|}
\hline 19 & Centro de Desenvolvimento Pessoal e Empresarial (Cedepe) & 1 \\
\hline 20 & Centro Paula Souza & 1 \\
\hline 21 & Escola Superior de Propaganda e Marketing (ESPM) & 1 \\
\hline 22 & Faculdade Novos Horizontes & 1 \\
\hline 23 & Instituto Federal de Minas Gerais (IFMG) & 1 \\
\hline 24 & Universidad Politécnica de Madrid (UPM) (Espanha) & 1 \\
\hline 25 & Universidade de Fortaleza & 1 \\
\hline 26 & Universidade de Passo Fundo - RS & 1 \\
\hline
\end{tabular}

Fonte: elaboração própria.

A partir da Tabela 4 foi possível perceber que os estados com mais pesquisadores relacionados ao tema são os estados de São Paulo e Rio de Janeiro, representando quase metade da produção total (44,35\%), seguidos dos pesquisadores do Distrito Federal, Santa Catarina, Rio Grande do Sul, Pernambuco e Minas Gerais, que juntos correspondem a 40\% da produção acadêmica. No Ceará e Paraná aparecem 5 pesquisadores. E os Estados do Amapá, Pará e Paraíba conta com apenas um pesquisador em cada Estado. Destaca-se, ainda, a participação de pesquisadores estrangeiros na produção nacional a respeito da temática, figurando nessa lista pesquisadores europeus e norte-americanos.

Tabela 4 | Autores por Estado

\begin{tabular}{|c|l|c|c|}
\hline Ordem & Estados & $\begin{array}{c}\text { Quantidade de } \\
\text { autores }\end{array}$ & $\%$ \\
\hline 1 & São Paulo (SP) & 33 & 26,6 \\
\hline 2 & Rio de Janeiro (RJ) & 22 & 17,7 \\
\hline 3 & Distrito Federal & 14 & 11,3 \\
\hline 4 & Santa Catarina (SC) & 12 & 9,7 \\
\hline 5 & Rio Grande do Sul (RS) & 9 & 7,3 \\
\hline 6 & Pernambuco (PE) & 8 & 6,5 \\
\hline 7 & Minas Gerais (MG) & 7 & 5,6 \\
\hline 8 & Ceará (CE) & 5 & 4,0 \\
\hline 9 & Paraná (PR) & 5 & 4,0 \\
\hline
\end{tabular}




\begin{tabular}{|c|l|c|c|}
\hline 10 & Amapá (AP) & 1 & 0,8 \\
\hline 11 & Pará (PA) & 1 & 0,8 \\
\hline 12 & Paraíba (PB) & 1 & 0,8 \\
\hline & & & \\
\hline 1 & Portugal & 1 & 3,2 \\
\hline 3 & Espanha & 1 & 0,8 \\
\hline & Estados Unidos & 1 & 0,8 \\
\hline
\end{tabular}

Fonte: elaboração própria.

Em relação à análise por regiões, o Gráfico 1 mostra que a Região Sudeste aparece com 62 autores no período, que corresponde a 50\% do total; e a Região Sul, com $21 \%$ (26 autores). O percentual das regiões Nordeste e Centro-Oeste representa 11\%, com 14 autores cada, e a Região Norte aparece com apenas 2 autores (2\%). Cabe ressaltar que a análise das regiões deve ser realizada em conjunto com a Tabela 4, tendo em vista que não houve publicação de autores em todos os estados abrangidos nas regiões.

\section{Gráfico 1 | Autores por Região}

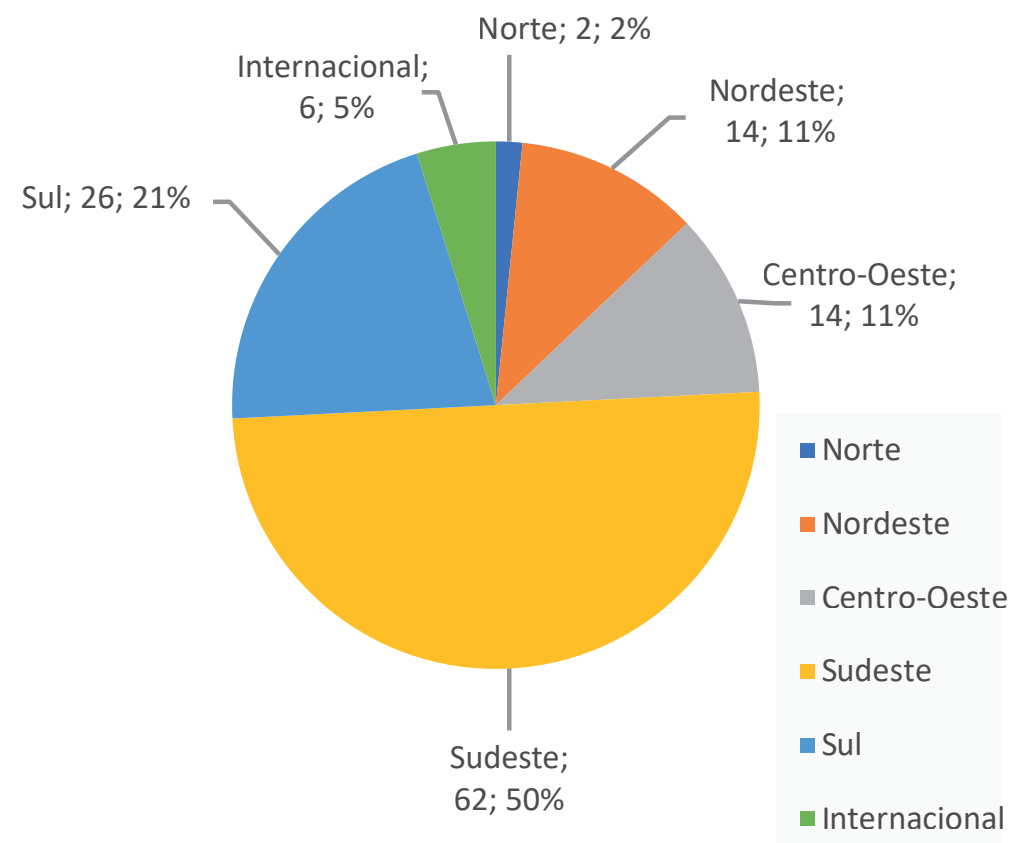

Fonte: elaboração própria. 
Assim, verifica-se que, no geral, as características do perfil de autoria das publicações sobre gestão de riscos são: possuir dois autores, os pesquisadores possuem a titulação de doutorado e estão vinculados às universidades do Sudeste, prevalecendo publicações de pesquisadores do Estado de São Paulo. Foi identificado também que não é recorrente a publicação de mais de um estudo sobre o mesmo tema pelo mesmo autor, com exceção de José Souza Neto, que publicou dois artigos no período pesquisado.

\subsection{Periódicos com mais publicações}

Na Tabela 5 são listados os periódicos que publicaram sobre a temática, com a quantidade de artigos publicados por periódico, bem como o ano das publicações. Ao todo foram 43 artigos publicados em 34 revistas.

Tabela 5 | Quantidade de artigos publicados por periódico

\begin{tabular}{|c|c|c|c|c|c|c|c|c|c|c|c|c|c|}
\hline $\begin{array}{l}\text { Identificação } \\
\text { do periódico }\end{array}$ & Qualis & 2008 & 2009 & 2010 & 2011 & 2012 & 2013 & 2014 & 2015 & 2016 & 2017 & 2018 & Total \\
\hline $\begin{array}{l}\text { Revista de } \\
\text { Gestão e } \\
\text { Projetos }\end{array}$ & B2 & & & & 1 & & & & & & 1 & & 2 \\
\hline $\begin{array}{l}\text { Revista } \\
\text { Universo } \\
\text { Contábil }\end{array}$ & $\mathrm{A} 2$ & & & & & & & & & 1 & & & 1 \\
\hline $\begin{array}{l}\text { Revista } \\
\text { Catarinense de } \\
\text { Ciência Contábil }\end{array}$ & B2 & & & & 1 & & & & & 1 & & & 2 \\
\hline $\begin{array}{l}\text { Rev. } \\
\text { Contemporânea } \\
\text { de } \\
\text { Contabilidade }\end{array}$ & A2 & & & & & & & 1 & & & & & 1 \\
\hline $\begin{array}{l}\text { Future Studies } \\
\text { Research } \\
\text { Journal }\end{array}$ & B2 & & & & & & & & & & 1 & & 1 \\
\hline $\begin{array}{l}\text { Rev. de Adm., } \\
\text { Ciên. Cont. e } \\
\text { Sustentab. }\end{array}$ & B2 & & & & & & & & & & 1 & & 1 \\
\hline
\end{tabular}




\begin{tabular}{|c|c|c|c|c|c|c|c|c|c|}
\hline $\begin{array}{l}\text { Perspectiva } \\
\text { em Gestão \& } \\
\text { Conhecimento }\end{array}$ & B3 & & & & & & & 1 & 1 \\
\hline $\begin{array}{l}\text { Rev. de Empre- } \\
\text { endedorismo } \\
\text { e Gest. de Peq. } \\
\text { Empresas }\end{array}$ & B1 & & & & & & & 1 & 1 \\
\hline $\begin{array}{l}\text { Rev. de Contab. } \\
\text { do Mest. em } \\
\text { Ciências Cont. } \\
\text { da UERJ }\end{array}$ & B2 & 1 & & & & & 1 & & 2 \\
\hline $\begin{array}{l}\text { Revista de } \\
\text { Economia e } \\
\text { Administração }\end{array}$ & B3 & & 1 & & & & & & 1 \\
\hline $\begin{array}{l}\text { Gestão \& } \\
\text { Regionalidade }\end{array}$ & B2 & & & 1 & & & & & 1 \\
\hline $\begin{array}{l}\text { International } \\
\text { Journal of } \\
\text { Innovation }\end{array}$ & B3 & & & & & 1 & & & 1 \\
\hline $\begin{array}{l}\text { Revista de } \\
\text { Ciências da } \\
\text { Administração }\end{array}$ & B1 & & & & 1 & & & & 1 \\
\hline $\begin{array}{l}\text { Revista } \\
\text { Contabilidade \& } \\
\text { Finanças }\end{array}$ & A2 & & & & & & 1 & & 1 \\
\hline $\begin{array}{l}\text { Revista do } \\
\text { Serviço Público }\end{array}$ & B2 & & & & 1 & & & 1 & 2 \\
\hline $\begin{array}{l}\text { Revista } \\
\text { Controle }\end{array}$ & B4 & & 1 & & & 1 & & & 2 \\
\hline $\begin{array}{l}\text { Revista ENIAC } \\
\text { Pesquisa }\end{array}$ & B3 & & & & & 1 & & & 1 \\
\hline $\begin{array}{l}\text { Revista } \\
\text { Eletrônica } \\
\text { Gestão \& Saúde }\end{array}$ & B3 & & & & 1 & & & & 1 \\
\hline $\begin{array}{l}\text { Revista Produ- } \\
\text { ção e Desenvol- } \\
\text { vimento }\end{array}$ & B3 & & & & & 1 & & & 1 \\
\hline
\end{tabular}




\begin{tabular}{|c|c|c|c|c|c|c|c|c|c|c|}
\hline $\begin{array}{l}\text { Gepros: Gestão } \\
\text { da Produção, } \\
\text { Operações e } \\
\text { Sistemas }\end{array}$ & B3 & & & & & & & & 1 & 1 \\
\hline $\begin{array}{l}\text { Revista } \\
\text { Brasileira de } \\
\text { Gestão de } \\
\text { Negócios }\end{array}$ & $\mathrm{A} 2$ & & & & & & 1 & & & 1 \\
\hline $\begin{array}{l}\text { Ambiente \& } \\
\text { Sociedade }\end{array}$ & B1 & & & & & 2 & & 1 & & 3 \\
\hline $\begin{array}{l}\text { Revista de Ges- } \\
\text { tão Ambiental } \\
\text { e Sustentabili- } \\
\text { dade }\end{array}$ & B2 & & & 1 & & & & 1 & & 2 \\
\hline $\begin{array}{l}\text { Turismo em } \\
\text { Análise }\end{array}$ & B1 & 1 & & & & & & & & 1 \\
\hline $\begin{array}{l}\text { Revista Parana- } \\
\text { ense de Desen- } \\
\text { volvimento }\end{array}$ & B4 & & & & 1 & & & & & 1 \\
\hline Soc. \& Nat. & B2 & & & & 1 & & & & & 1 \\
\hline $\begin{array}{l}\text { Revista Espaço } \\
\text { Acadêmico }\end{array}$ & B3 & & & & & & 1 & & & 1 \\
\hline Territorium & B4 & & & & 1 & 1 & & & & 2 \\
\hline $\begin{array}{l}\text { Revista } \\
\text { Eletrônica de } \\
\text { Administração }\end{array}$ & B1 & & 1 & & & & & & & 1 \\
\hline $\begin{array}{l}\text { RA'E GA: } \\
\text { O espaço } \\
\text { geográfico em } \\
\text { análise }\end{array}$ & B4 & & & & 1 & & & & & 1 \\
\hline $\begin{array}{l}\text { Sustentabilida- } \\
\text { de em Debate }\end{array}$ & B4 & & & & & & 1 & & & 1 \\
\hline $\begin{array}{l}\text { Revista de } \\
\text { Gestão Costeira } \\
\text { Integrada }\end{array}$ & B1 & & & & & & & 1 & & 1 \\
\hline
\end{tabular}




\begin{tabular}{|l|l|l|l|l|l|l|l|l|}
\hline $\begin{array}{l}\text { Boletim } \\
\text { Geográfico do } \\
\text { Rio Grande do } \\
\text { Sul }\end{array}$ & C & & & & & & & \\
\hline
\end{tabular}

Fonte: elaboração própria.

Conforme demonstrado na Tabela 6, os periódicos que mais publicaram a respeito do tema foram: Ambiente \& Sociedade, com 3 artigos; Revista de Gestão e Projetos, Revista Catarinense de Ciência Contábil, Revista de Contabilidade do Mestrado em Ciências Contábeis da UERJ, Revista do Serviço Público, Revista Controle, Revista de Gestão Ambiental e Sustentabilidade e Territorium, com 2 artigos cada. As demais publicaram apenas um artigo. Destaca-se a diversificação de periódicos com publicações sobre gestão de riscos, indicando a importância do tema e do interesse da comunidade científica sobre ele. No entanto, percebe-se um número reduzido de publicações por periódico, que pode representar a baixa maturidade da pesquisa sobre gestão de riscos.

\section{Tabela 6 | Periódicos com mais publicações}

\begin{tabular}{|l|l|l|}
\hline Identificação da revista & Qualis & Total \\
\hline Ambiente \& Sociedade & $B 1$ & 3 \\
\hline Revista de Gestão e Projetos & $B 2$ & 2 \\
\hline Revista Catarinense de Ciência Contábil & $B 2$ & 2 \\
\hline Rev. de Contab. do Mest. em Ciências Cont. da UERJ & $B 2$ & 2 \\
\hline Revista do Serviço Público & $B 2$ & 2 \\
\hline Revista Controle & $B 4$ & 2 \\
\hline Revista de Gestão Ambiental e Sustentabilidade & $B 2$ & 2 \\
\hline Territorium & $B 4$ & 2 \\
\hline
\end{tabular}

Fonte: elaboração própria. 
Para melhor entender a Tabela 7, é preciso discorrer a respeito da classificação Qualis. Conforme informações disponibilizadas no sítio da Capes, essa classificação consiste em procedimentos utilizados para estratificação da qualidade da produção intelectual. Desta forma, a Qualis afere a qualidade dos artigos e de outros tipos de produção, a partir da análise da qualidade dos periódicos, que são enquadrados em estratos indicativos da qualidade que vão de $\mathrm{A} 1 \mathrm{a} \mathrm{C}$, sendo $\mathrm{A} 1$ o estrato mais elevado.

Tabela 7 | Perfil dos periódicos com publicações

\begin{tabular}{|c|c|c|c|}
\hline Ordem & Qualis & Quantidade de artigos & $\%$ \\
\hline 1 & B2 & 14 & 32,6 \\
\hline 2 & B3 & 8 & 18,6 \\
\hline 3 & B1 & 8 & 18,6 \\
\hline 4 & B4 & 7 & 16,3 \\
\hline 5 & A2 & 5 & 11,6 \\
\hline 6 & C & 1 & 2,3 \\
\hline
\end{tabular}

Fonte: elaboração própria.

A partir da análise da Tabela 7, é possível observar que a grande maioria dos artigos sobre gestão de riscos foram publicados em periódicos pertences à categoria $B$, sendo 14 na B2, 8 na B3, 8 na B1 e 7 na B4. Na categoria A2 foram publicados 5 artigos, e apenas 1 na categoria C. Do total de artigos, verifica-se que 30,2\% foram publicados em revistas classificadas como de alto impacto, sendo 5 em revistas A2 e 8 em revistas B1. Esses dados atestam a qualidade dos artigos publicados e demonstram a representatividade em revistas consideradas de alto padrão.

\subsection{Aspectos metodológicos}

No que diz respeito aos aspectos metodológicos, os artigos foram inicialmente classificados quanto à abordagem utilizada na pesquisa, conforme pode-se observar na Tabela 8. Nota-se que os autores não apresentaram, para uma parcela relevante dos artigos analisados (46,5\%), a classificação em relação à abordagem utilizada. Nos artigos que delimitaram a pesquisa quanto à abordagem utilizada, houve predomínio da utilização de abordagem qualitativa, aproximadamente $40 \%$ dos artigos analisados. Já $11,6 \%$ dos 
artigos analisados combinaram as duas abordagens e somente um único artigo (2,3\%) utilizou exclusivamente abordagem quantitativa. Um motivo que pode ser apontado para a predomínio de pesquisas qualitativas é a complexidade do tema gestão de riscos, o que requer um diagnóstico mais minucioso do objeto de estudo. Beuren (2008) observa que, nas pesquisas qualitativas, realiza-se uma análise mais profunda em relação ao fenômeno estudado.

Tabela 8 | Classificação quanto à abordagem

\begin{tabular}{|c|l|c|c|}
\hline Ordem & Classificação quanto à abordagem & $\begin{array}{c}\text { Quantidade de } \\
\text { artigos }\end{array}$ & $\%$ \\
\hline 1 & Não especificada no artigo & 20 & 46,5 \\
\hline 2 & Qualitativa & 17 & 39,5 \\
\hline 3 & Qualitativa e Quantitativa & 5 & 11,6 \\
\hline 4 & Quantitativa & 1 & 2,3 \\
\hline
\end{tabular}

Fonte: elaboração própria.

Na Tabela 9 é apresentada a classificação dos estudos quanto aos procedimentos adotados. A exemplo do que ocorreu com a classificação quanto à abordagem, a maior parcela dos artigos analisados (34,9\%) não informou os procedimentos adotados nos estudos. O estudo de caso foi o método preponderante, sendo utilizado em 30,2\% dos artigos. Os trabalhos que utilizaram esse procedimento analisaram como se deu a implantação de ferramentas de gestão de riscos em entes públicos e os impactos advindos da adoção de instrumentos de gestão de riscos. Gil (2010) observa que o estudo de caso é utilizado quando é necessário efetuar um estudo profundo e exaustivo de um ou mais objetos, proporcionando um conhecimento amplo e detalhado. Outros procedimentos utilizados de forma isolada ou combinada foram: pesquisa bibliográfica, pesquisa documental, análise bibliométrica, survey, pesquisa de campo, análise de conteúdo, pesquisa-ação e revisão bibliográfica. 
Tabela 9 | Classificação quanto aos procedimentos

\begin{tabular}{|c|c|c|c|}
\hline Ordem & $\begin{array}{l}\text { Classificação quanto aos } \\
\text { procedimentos }\end{array}$ & $\begin{array}{l}\text { Quantidade de } \\
\text { artigos }\end{array}$ & $\%$ \\
\hline 1 & Não especificado no artigo & 15 & 34,9 \\
\hline 2 & Estudo de caso & 13 & 30,2 \\
\hline 3 & Pesquisa bibliográfica & 3 & 7,0 \\
\hline 4 & Pesquisa bibliográfica e pesquisa documental & 2 & 4,7 \\
\hline 5 & Análise bibliométrica, pesquisa documental e survey & 1 & 2,3 \\
\hline 6 & Pesquisa bibliográfica e pesquisa de campo & 1 & 2,3 \\
\hline 7 & Pesquisa bibliográfica e análise de conteúdo & 1 & 2,3 \\
\hline 8 & Análise de conteúdo & 1 & 2,3 \\
\hline 9 & Estudo de caso e pesquisa bibliográfica & 1 & 2,3 \\
\hline 10 & Estudo de caso e análise de conteúdo & 1 & 2,3 \\
\hline 11 & Pesquisa documental & 1 & 2,3 \\
\hline 12 & $\begin{array}{l}\text { Pesquisa documental, pesquisa-ação e survey } \\
\text { (triangulação) }\end{array}$ & 1 & 2,3 \\
\hline 13 & Pesquisa bibliográfica e survey & 1 & 2,3 \\
\hline 14 & Revisão bibliográfica & 1 & 2,3 \\
\hline
\end{tabular}

Fonte: elaboração própria.

Em relação à classificação das pesquisas quanto aos objetivos, a análise foi substancialmente comprometida, já que, em $72 \%$ dos artigos analisados, não se especificou esse tipo de classificação metodológica. Nos artigos em que foi informada a classificação quanto aos objetivos, houve a predominância de pesquisas exploratórias (14\%), o que se justifica por se tratar de uma temática de pesquisa recente. De acordo com Beuren (2008), esse tipo de estudo é apropriado para situações em que há pouco conhecimento sobre a temática, em que se busca conhecer mais profundamente um assunto, tornando-o mais claro. Também foram identificadas pesquisas descritivas $(9,3 \%)$ e pesquisas concomitantemente descritivas e exploratórias (4,7\%). 
Tabela 10 | Classificação quanto aos objetivos

\begin{tabular}{|l|l|c|c|}
\hline Ordem & $\begin{array}{l}\text { Classificação quanto aos } \\
\text { objetivos }\end{array}$ & $\begin{array}{c}\text { Quantidade de } \\
\text { artigos }\end{array}$ & $\%$ \\
\hline 1 & Não especificado no artigo & 31 & 72,01 \\
\hline 2 & Pesquisa exploratória & 6 & 14,0 \\
\hline 3 & Pesquisa descritiva & 4 & 9,3 \\
\hline 4 & Pesquisa descritiva e exploratória & 2 & 4,7 \\
\hline
\end{tabular}

Fonte: elaboração própria.

Os estudos também foram classificados quanto às técnicas de coletas de dados utilizadas. Pode ser observado, na Tabela 11, que 51,2\% dos artigos não informaram as técnicas utilizadas para coleta de dados. Nesse aspecto predominou a combinação de dados secundários com entrevistas $(20,9 \%)$, seguido por dados secundários somente (11,6\%), questionários (4,7\%), entrevistas (4,7\%). Também foram identificados trabalhos que utilizaram entrevistas e questionários (2,3\%), dados secundários e questionários $(2,3 \%)$ e observação direta e entrevistas (2,3\%). Observa-se que a utilização de dados secundários foi preponderante tanto em conjunto com outras técnicas como de forma única. Uma explicação para isto pode advir do foco utilizado no estudo. Na administração pública, predomina a formalidade dos atos, existindo a preocupação em normatizar os procedimentos. Boaventura (2004) observa que os documentos públicos costumam ser a fonte mais utilizada para pesquisas documentais, citando alguns tipos de documentos como leis, decretos e regulamentos. Outra técnica de coleta de dados de utilização frequente nos estudos analisados foi a realização de entrevistas. Gray (2012) observa que as entrevistas tendem a ser a melhor abordagem de coleta de dados em pesquisas do tipo exploratório, em que o pesquisador pode aprofundar as respostas. Isso reforça o resultado apresentado na Tabela 10, onde se observa a predominância de estudos do tipo exploratório. 
Tabela 11 | Técnicas de coleta de dados dos artigos pesquisados

\begin{tabular}{|c|l|c|c|}
\hline Ordem & Técnicas de coleta de dados & $\begin{array}{c}\text { Quantidade de } \\
\text { artigos }\end{array}$ & $\%$ \\
\hline 1 & Não especificado no artigo & 22 & 51,2 \\
\hline 2 & Dados secundários e entrevistas & 9 & 20,9 \\
\hline 3 & Dados secundários & 5 & 11,6 \\
\hline 4 & Questionário & 2 & 4,7 \\
\hline 5 & Entrevistas & 2 & 4,7 \\
\hline 6 & Entrevista e questionário & 1 & 2,3 \\
\hline 7 & Dados secundários e questionários & 1 & 2,3 \\
\hline 8 & Observação direta e entrevistas & 1 & 2,3 \\
\hline
\end{tabular}

Fonte: elaboração própria.

\subsection{Setores mais estudados}

Os setores mais estudados nas publicações analisadas, conforme exposto na Tabela 12, foram a administração pública municipal com 9 artigos e a administração pública estadual com 8 artigos, que juntos correspondem a quase 40\% dos artigos publicados. Outros campos analisados foram: instituições de ensino, instituições de saúde, instituições financeiras, administração pública federal, o sistema "S", agências reguladoras, instituições de pesquisa e órgãos de controle.

\section{Tabela 12 | Setores mais estudados}

\begin{tabular}{|c|l|c|c|}
\hline Ordem & Setor & $\begin{array}{c}\text { Quantidade } \\
\text { de artigos }\end{array}$ & $\%$ \\
\hline 1 & Administração pública municipal & 9 & 20,9 \\
\hline 2 & Administração pública estadual & 8 & 18,6 \\
\hline 3 & Sem setor específico & 7 & 16,3 \\
\hline 4 & Forças armadas & 3 & 7,0 \\
\hline 5 & Instituições de ensino & 3 & 7,0 \\
\hline 6 & Instituições de saúde & 3 & 7,0 \\
\hline 7 & Instituições financeiras & 3 & 7,0 \\
\hline
\end{tabular}




\begin{tabular}{|c|l|c|c|}
\hline 8 & Administração pública federal & 2 & 4,7 \\
\hline 9 & Sistema "S" & 2 & 4,7 \\
\hline 10 & Agências reguladoras & 1 & 2,3 \\
\hline 11 & Instituições de pesquisa & 1 & 2,3 \\
\hline 12 & Órgãos de controle & 1 & 2,3 \\
\hline
\end{tabular}

Fonte: elaboração própria.

\subsection{Eixos temáticos correlatos}

A partir da análise da Tabela 13, percebe-se a expressiva quantidade de eixos temáticos correlatos e sua variabilidade. Nos estudos de Ribeiro (2017), por exemplo, foram identificados 29 temas que se vinculam ao assunto, um número ainda mais elevado do que o encontrado nesta pesquisa (16). O eixo temático que mais se destacou nesta pesquisa foi gestão ambiental, com 15 artigos, que equivale a 34,9\% da produção do período analisado. Nota-se uma grande diferença na quantidade de artigos sobre esse eixo temático quando comparado com os demais, o que evidencia a intensa preocupação dos pesquisadores com a categoria riscos ambientais. Os outros temas mais representativos são: tecnologia da informação, com 11,6\%; gestão de projetos, com 9,3\%; controle interno e riscos operacionais, com $7 \%$ cada; aquisições e políticas públicas, com 4,7\% cada; e comunicação, corrupção, empreendedorismo, gestão de suprimentos, governança corporativa, inovação, previdência social, riscos estratégicos e terceirização, com 2,3\% cada.

\section{Tabela 13 | Principais eixos temáticos}

\begin{tabular}{|r|l|c|c|}
\hline Ordem & Tema central & $\begin{array}{c}\text { Quantidade de } \\
\text { artigos }\end{array}$ & $\%$ \\
\hline 1 & Gestão ambiental & 15 & 34,9 \\
\hline 2 & Tecnologia da informação & 5 & 11,6 \\
\hline 3 & Gestão de projetos & 4 & 9,3 \\
\hline 4 & Controle interno & 3 & 7,0 \\
\hline 5 & Riscos operacionais & 3 & 7,0 \\
\hline 6 & Aquisições & 2 & 4,7 \\
\hline
\end{tabular}




\begin{tabular}{|c|l|c|c|}
\hline 7 & Políticas públicas & 2 & 4,7 \\
\hline 8 & Comunicação & 1 & 2,3 \\
\hline 9 & Corrupção & 1 & 2,3 \\
\hline 10 & Empreendedorismo & 1 & 2,3 \\
\hline 11 & Gestão de suprimentos & 1 & 2,3 \\
\hline 12 & Governança corporativa & 1 & 2,3 \\
\hline 13 & Inovação & 1 & 2,3 \\
\hline 14 & Previdência social & 1 & 2,3 \\
\hline 16 & Riscos estratégicos & 1 & 2,3 \\
\hline
\end{tabular}

Fonte: elaboração própria.

\subsection{Modelos teóricos}

A partir da análise da Tabela 14, observa-se um grande número de artigos (21) sem definição de um modelo teórico específico.

\section{Tabela 14 | Modelos teóricos citados}

\begin{tabular}{|l|c|}
\hline Modelo & $\begin{array}{c}\text { Quantidade de } \\
\text { artigos }\end{array}$ \\
\hline ABNT & 1 \\
\hline ABNT e ISACA & 1 \\
\hline CCMD - Centro Canadense para o Desenvolvimento da Gestão & 1 \\
\hline Comitê de Basiléia & 2 \\
\hline COSO & 4 \\
\hline COSO, ISO 31000 & 1 \\
\hline Dwyer (2005) & 1 \\
\hline IBGC, Federation of European Risk Management Association (FERMA); COSO & 1 \\
\hline ISO/IEC & 1 \\
\hline Marco de Ação de Hyogo & 1 \\
\hline Método dos momentos-L & 1 \\
\hline Metodologia Scrum & 1 \\
\hline Não especificado & 21 \\
\hline
\end{tabular}


NIST 800-100 e Norma ABNT

PMBOK (Projetos)

SHALSTAB

1

4

1

Fonte: elaboração própria.

Constatou-se a ampla diversidade de modelos citados, que pode ser explicada, em parte, pela variedade de eixos temáticos. Dos modelos teóricos utilizados para gestão de riscos, o coso foi o que mais se destacou aparecendo isoladamente em 4 artigos e em conjunto com outros temas em mais dois artigos. Esses dados se coadunam com a definição do COSO como modelo a ser adotado na administração pública federal a partir da publicação da Instrução Normativa conjunta CGU/MP no 01/2016. O resultado também corrobora o estudo de Valentim, Silva e Passos (2016), que aponta o COSO como instrumento de controle e gestão em diversos trabalhos.

\subsection{Dinâmica da produção científica}

Nesta seção analisa-se a dinâmica da produção científica no período de 2008 a 2018.

\section{Gráfico 2 | Dinâmica da produção científica}

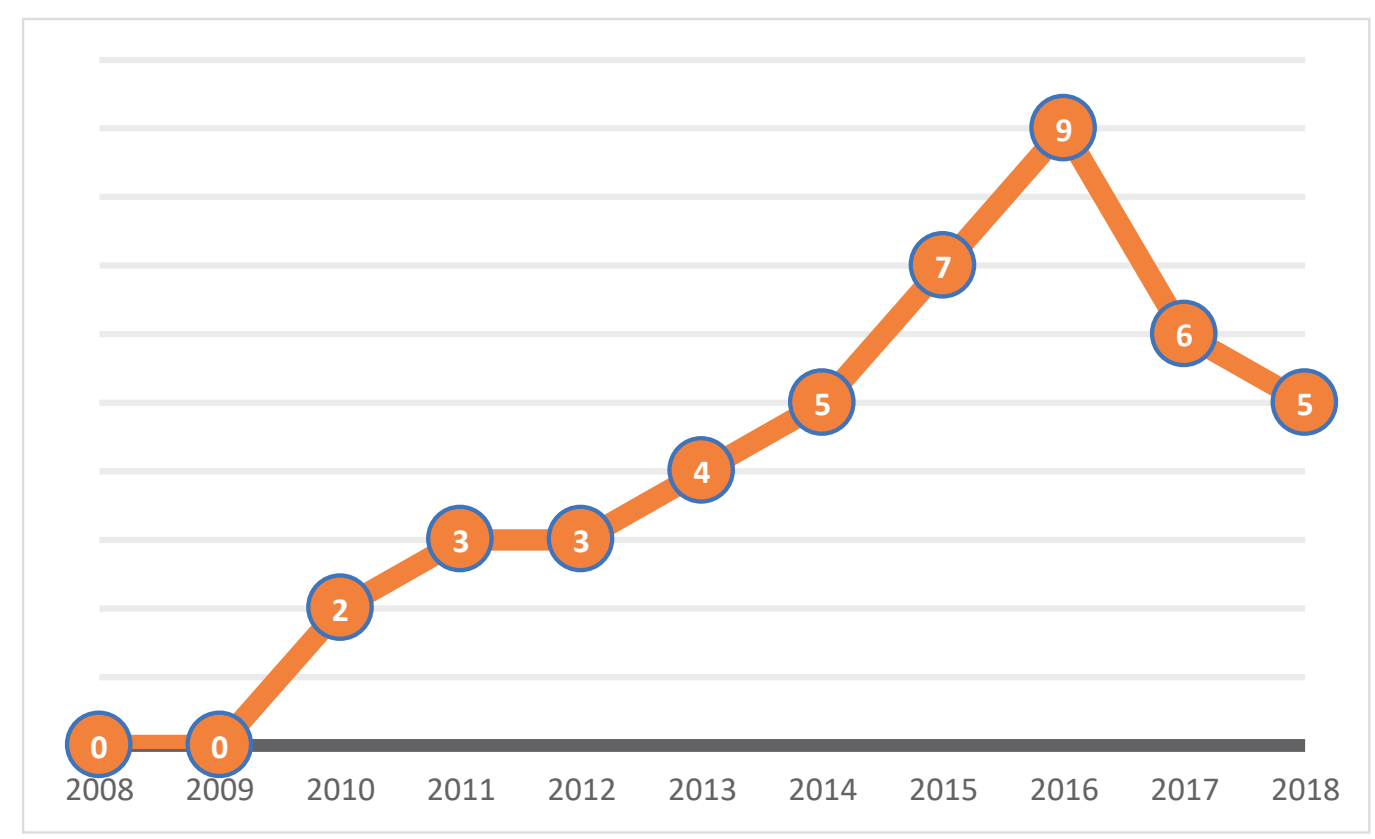

Fonte: elaboração própria. 
A partir da análise do Gráfico 2, é possível perceber a evolução das publicações referentes à temática até o exercício de 2016, quando se registra o maior número de artigos, e a partir disso um declínio. No que concerne à gestão de riscos sob a ótica de controles internos, acredita-se que a explicação se dá pelo contexto de crescimento das discussões nacionais a respeito do tema, como demonstrado nos estudos de Silva, Abreu e Couto (2017), em que se constatou um aumento na emissão de normativos, sobretudo após a divulgação do processo de apuração das denúncias apresentadas na Operação Lava Jato.

\section{Conclusão}

O estudo foi norteado pela questão de pesquisa: como se caracteriza a produção científica brasileira sobre gestão de riscos no setor público? Os resultados apresentados permitiram responder a essa indagação, atendendo assim o objetivo geral da pesquisa, que foi investigar a produção científica de artigos sobre gestão de riscos com enfoque no setor público, publicada em periódicos nacionais.

O primeiro objetivo específico foi analisar o perfil de autoria que mais se destacou na produção acadêmica acerca da temática. Os resultados apontam que, no geral, as características do perfil de autoria das publicações sobre gestão de riscos são: possuir dois autores, os pesquisadores possuem a titulação de doutorado e estão vinculados às universidades do Sudeste, prevalecendo publicações de pesquisadores do estado de São Paulo. Foi identificado também que não é recorrente a publicação de mais de um estudo sobre o mesmo tema pelo mesmo autor, com exceção de José Souza Neto, que publicou dois artigos no período pesquisado.

Quanto à identificação do perfil dos periódicos que publicam sobre o tema, segundo objetivo específico, constatou-se diversificação de periódicos com publicações, indicando a importância do tema e do interesse da comunidade científica sobre ele. No entanto, percebe-se um número reduzido de publicações por periódico, que pode representar a baixa maturidade da pesquisa sobre gestão de riscos. O periódico com mais publicações é o Ambiente \& Sociedade, o único com mais de 2 artigos publicados. A grande maioria 
dos artigos sobre gestão de riscos foram publicados em periódicos pertences à categoria Qualis B. Isso demonstra a representatividade em revistas consideradas de alto padrão.

O terceiro objetivo específico definido foi conhecer os aspectos metodológicos. Não obstante a falta de informações sobre aspectos metodológicos em muitos dos artigos analisados, pode-se identificar que, quanto à abordagem, as pesquisas foram predominantemente qualitativas. O procedimento mais frequentemente utilizado pelos autores foi o estudo de caso. Já em relação à classificação metodológica quanto aos objetivos, dos artigos que informaram essa classificação, a maioria foi do tipo exploratória. O método de coleta de dados mais frequente foi o uso de dados secundários, sendo também utilizadas entrevistas. Constata-se que os estudos são predominantemente qualitativos, o que permite inferir que, enfrentada a fase exploratória do tema, há oportunidades para realização de estudos com abordagem quantitativa.

Sobre o quarto objetivo, o de conhecer o tipo de organização ou setor mais estudado quanto ao aspecto gestão de riscos, identificou-se que a administração pública municipal e a administração pública estadual foram os campos mais estudados pelos pesquisadores.

No tocante aos principais eixos temáticos, quinto objetivo específico, observouse a variabilidade de temas correlatos, estando a gestão ambiental no topo dos mais publicados, o que evidencia a intensa preocupação dos pesquisadores com a categoria riscos ambientais.

Em relação ao sexto objetivo específico, que era conhecer os modelos teóricos predominantes nos estudos, constatou-se a ampla diversidade de modelos citados, que pode ser explicada, em parte, pela variedade de eixos temáticos. Dos modelos teóricos utilizados para gestão de riscos, o COSO foi o que mais se destacou, o que se coaduna com a definição do COSO como modelo a ser adotado na administração pública federal, a partir da publicação da Instrução Normativa conjunta CGU/MP no 01/2016.

No que tange ao sétimo objetivo específico, o de verificar a dinâmica da produção científica, os resultados apontam uma evolução na produção acadêmica entre o período de 2008 a 2016, sendo este último o ano de maior produção acadêmica, com 9 artigos publicados. A partir desse período, registra-se um declínio no número de publicações. 
A presente pesquisa apresenta como contribuição uma análise quantitativa das publicações sobre gestão de riscos no setor público, enfocando o perfil de autoria, as características dos periódicos que publicam sobre o tema, a evolução da produção científica, os procedimentos metodológicos adotados, os temas recorrentes, os setores mais pesquisados e os modelos teóricos mais citados.

A partir dos resultados da pesquisa, é possível diversificar o estudo da gestão de riscos no setor público e identificar temas, setores e metodologias que estão sendo menos exploradas e precisam de mais atenção. Dessa forma, este trabalho contribui para o estudo da gestão de riscos por mostrar os limites do campo e os aspectos que precisam ser mais bem desenvolvidos, representando um avanço para essas áreas de estudo.

Ressalta-se a amplitude e significância desta produção, além de seu enfoque específico, tendo em vista que não foram encontrados trabalhos voltados à gestão de riscos sob a perspectiva de aplicabilidade ao setor público.

Sugere-se a replicação deste estudo com a utilização de outras bases, sobretudo aquelas relacionadas às teses e dissertações, assim como em anais dos eventos da Associação Nacional de Pós-Graduação e Pesquisa em Administração (Anpad).

\section{Referências bibliográficas}

ACEvedo, C. R.; Nohara, J. J. Monografia no curso de Administração: guia completo de conteúdo e forma. 2. ed. São Paulo: Atlas, 2006.

ARAúso, C. A. Bibliometria: evolução histórica e questões atuais. Em Questão, Porto Alegre, v. 12, n. 1, p. 11-32, 2006.

ASSOCIAÇÃO BRASILEIRA DE NORMAS TÉCNICAS (ABNT). Gestão de riscos: princípios e diretrizes, ISO 31000:2009. Disponível em: <https://gestravp.files.wordpress.com/2013/06/iso31000-gestc3a3ode-riscos.pdf $>$. Acesso em: 10/05/2019.

ÁvILA, M. D. G. Gestão de riscos no setor público. Revista Controle: doutrina e artigos, v. 12, n. 2, p. 179-198, 2014.

BEUREN, Ilse Maria. Como elaborar trabalhos monográficos em contabilidade: teoria e prática. 3. 
ed. São Paulo: Atlas, 2008.

BoAventurA, E. M. Metodologia da pesquisa: monografia, dissertação, tese. São Paulo: Atlas, 2004.

Carvalho Neto, A. A.; Silva, L. C. Critérios gerais de controle interno na administração pública: um estudo dos modelos e das normas disciplinadoras em diversos países. Brasília: Tribunal de Contas da União. 2009.

COMmitTeE of Sponsoring Organizations of the TREAdWAy Comission (COSO).

Gerenciamento de riscos corporativos - Estrutura Integrada: Sumário Executivo. São Paulo:

PricewaterhouseCoopers, 2007.

DAMODARAN, A. Investment philosophies: successful investment philosophies and the greatest investors who made them work. New York: Wiley and Sons, 2003.

Gespública. Ministério do Planejamento, OrÇAmento e Gestão. Programa Nacional de Gestão Pública e Desburocratização: GesPública. Guia de orientação para o gerenciamento de riscos. Brasília: MPOG, 2013. Disponível em: <http://www.gespublica.gov.br/sites/default/files/ documentos/p_vii_risco_oportunidade.pdf>. Acesso em 20/05/2019.

GIL, A. C. Métodos e técnicas de pesquisa social. São Paulo: Atlas, 1987.

GraY, D. E. Pesquisa no mundo real. Porto Alegre: Penso, 2012.

MARTINS, M. A. F. et al. Seção temática: "Sistema de governança em órgãos públicos" Política de gestão de riscos corporativos: o caso de uma agência reguladora da saúde. Rev. Serv. Público, Brasília, v. 69, n. 1, p. 7-32, jan/mar. 2018.

Peleias, I. R.; Caetano, G.; Parisı, C.; Pereira, A. C. Produção científica sobre controle interno e gestão de riscos no ENANPAD e Congresso USP: análise bibliométrica no período 2001-2011. Revista Universo Contábil, Blumenau, v. 9, n. 4, p. 29-49, out./dez., 2013.

RIBEIRO, H. C. M. Produção acadêmica dos artigos publicados em revistas científicas nacionais disponibilizadas na Base Atena sobre o tema gestão de riscos de 2000 a 2015. Revista Evidenciação Contábil \& Finanças, João Pessoa, v. 5, n. 1, p. 75-93, jan./abr. 2017.

Richardson, R. J. Pesquisa social: métodos e técnicas. 2. ed. São Paulo: Atlas, 1989.

SILVA, B. J. P. Proposta de modelo de gestão de riscos para uma IFES visando à realização de auditoria baseada em riscos. 2015. 186 f. Dissertação (Mestrado) - Universidade Federal do Rio Grande do Norte. Centro de Ciências Humanas, Letras e Artes - Programa de Pós-Graduação em Gestão de Processos Institucionais.

Silva, A. H. C.; ABREU, C. L.; Couto, D. C. F. Evolução do controle interno no setor público: um estudo dos novos normativos emitidos entre 2003-2016. Revista de Contabilidade do Mestrado em Ciências Contábeis da UERJ (online), Rio de Janeiro, v. 22, p. 20-38, mai./ago. 2017.

VAlentim, I. C. D.; SILVA, L. O.; PASSOS, J. G. Controle interno e gestão de risco: uma revisão baseada em estudos brasileiros. Revista Interface, ]3, n. 1, p. 69-89, jan./jul. 2016. 


\section{Naiara Taise Sousa Nunes}

(iD) https://orcid.org/0000-0003-2495-213X

Possui graduação em Ciências Contábeis pela Universidade Federal do Piauí (2014). Especialista em Contabilidade e Orçamento Público pelo Centro de Ensino Unificado de Teresina (2015). Mestranda em Administração e Controladoria pela Universidade Federal do Ceará. Atualmente é contadora da Universidade Federal do Ceará. Tem experiência na área de Administração, com ênfase em contabilidade, controle e orçamento público.

E-mail: naiarataise@gmail.com

\section{Samuel Cavalcante Mota}

https://orcid.org/0000-0001-9197-1467

Possui graduação em Ciências Contábeis pela Universidade Estadual do Ceará (2006) e em Administração pela Universidade Federal do Ceará (2019). É mestrando em Administração e Controladoria pela Universidade Federal do Ceará. É servidor técnico-administrativo, no cargo de contador da Universidade Federal do Ceará.

E-mail: samuelcmota@hotmail.com

\section{Augusto Cézar de Aquino Cabral}

(iD) https://orcid.org/0000-0001-8248-4886

Possui graduação em Administração pela Universidade de Fortaleza (1988), mestrado em Administração pela Universidade Estadual do Ceará (1996), mestrado em Educação pela Universidade de New Hampshire - EUA (1991) e doutorado em Administração pela Universidade Federal de Minas Gerais (2001). É Professor Titular da Universidade Federal do Ceará, onde atua no Programa de Pós-Graduação em Administração e Controladoria (PPAC), nos campos dos estudos organizacionais e da gestão de pessoas.

E-mail: cabral@ufc.br

\section{Sandra Maria dos Santos}

(D) https://orcid.org/0000-0002-8515-9146

Possui graduação em Ciências Econômicas pela Universidade Federal do Ceará (1978), mestrado em Economia pela Universidade Federal do Ceará (1989) e doutorado em Economia pela Universidade Federal de Pernambuco (1998). Professora titular da Faculdade de Economia, Administração, Atuaria e Contabilidade (FEAAC), da Universidade Federal do Ceará (UFC), atuando na graduação e pós-graduação (Programa de Pós-Graduação em Administração e Controladoria PPAC).

E-mail: smsantos@ufc.br 